\title{
Expanding State Research Capacity in Child Welfare: The Need for State Institutional Review Boards (IRBs)
}

\section{Elisabeth S. Wilson ${ }^{1}$, $\underline{\text { Heather Hendley }}^{1}$, Rachel D. Russell ${ }^{1}$, $\underline{\text { Heather H. Kestian }}^{1}$, Terry I. Stigdon ${ }^{1}$}

${ }^{1}$ Indiana Department of Child Services, Indianapolis, IN

https://doi.org/10.38126/ISPG190113

Corresponding author: elisabeth.wilson@dcs.in.gov

Keywords: IRB, human subjects research, child welfare, practice-based research

Executive Summary: In 2018, funding for child welfare programs drastically changed under the Bipartisan Budget Act: Family First Prevention Services Act (FFPSA). To pull Title IV-E funding for prevention programs, all states must evaluate outcomes of children and families involved in child welfare. To meet these guidelines, state agencies need research structures, including internal Institutional Review Boards (IRBs). IRBs allow state governments to conduct ethical research, and expand research within the discipline. As researchers pursue careers outside of academia, these structures are pivotal and lead to policy contributions and knowledge in the discipline. This study evaluates the following in all 50 US states: How many states have internal IRBs? How many states have IRBs that are accessible to the state's child welfare agency? How have states set-up internal IRBs to function within a government context? The analysis found 34 states have at least one federally registered IRB of which 31 appear active within the state. However, only 11 of the 31 states have an IRB accessible to child welfare departments. These 11 states provide a blueprint for how to establish and maintain an IRB that supports child welfare agencies. Three distinct set ups emerged: holistic multi-department IRB, singular department/agency IRB, or those governed by an inter-agency sharing agreement. These findings show multiple states use an internal IRB to support state researchers. However, these IRBs are not currently accessible to the child welfare agency. For agencies to meet the requirements of FFPSA, IRBs must be expanded to the child welfare agency or built within the state.

\section{Introduction}

Federal agencies are continually writing policies and best practices that promote the importance of evidence-based decision making within the government. However, for child welfare, evidence-based decision making, and rigorous evaluation became required by federal law under the Family First Prevention Services Act (FFPSA) in 2018 (FFPSA 2018). FFPSA dictates that to receive federal funding, states must conduct rigorous evaluations of internal programs for rating by the Title IV-E clearinghouse and use the evidence-based programs that are rated by the Title IV-E clearinghouse (FFPSA 2018).

Since the law's passage, the call to bring research and evaluation teams into state child welfare agencies has significantly increased. As governments strive to increase the evaluation capacity and use of evidence-based decision making, increasing research structures within child welfare agencies is pivotal. In order for the state government to retain researchers as they transition from academic institutions, they will need access to an Institutional Review Board 
(IRB) to comply with federal law and conduct ethical evaluations. IRBs are required to oversee state-sanctioned research and protect human research subjects. Through setting up internal state IRBs, agencies allow researchers outside of universities to perform ethical human subjects research, contribute to their academic discipline, and instruct policy.

\section{i. Understanding Child Welfare Funding and the} Implications of FFPSA

The "Bipartisan Budget: Family's First Prevention Services Act of 2018" changed child welfare funding by modifying how states could use Title IV-E funds (id. At 170). Prior to FFPSA, Title IV-E funding supported children in out-of-home care including foster care, adoption assistance, and guardianship assistance programs (Social Security Act 1995).

FFPSA fundamentally changed the focus of the Title IV-E federal support from out-of-home foster care to in-home prevention services, (Social Security Act as amended 2018). The shift in this funding asks states to focus on services and interventions that they can provide for families to keep children in their home of origin. In addition, not only did the law change to allow for support of in-home care programs, the eligibility for in-home programs for Title IV-E funding was directly tied to the strength of sustained, statistical significance of the program. The validity of statistical evidence is determined by the creation of the Title IV-E Prevention Services Clearinghouse, and the requirements dictated under The Prevention Services Clearinghouse Handbook of Standards and Procedures as dictated by the FFPSA, (Social Security Act Section 470 et seq).

\section{ii. Research Requirements Dictated by FFPSA}

Under The Prevention Services Clearinghouse Handbook of Standards and Procedures, states must use specific guidelines when assessing and evaluating programs for use within the state if they are to pull Title IV-E funding. All programs must be evaluated and rated by the Title IV-E Prevention Services Clearinghouse to receive federal funding as established by the Social Security Act as amended in 2018. In order for a program or practice to be eligible for potential Title IV-E prevention funding, the program must meet the following general requirements of the Title IV-E Prevention Services Clearinghouse (Wilson et al. 2019):

- The practice/program must have a book or manual that specifies the protocol and practice,

- There is no empirical basis suggesting that compared to its likely benefits, the practice constitutes a risk of harm to those receiving it,

- If multiple outcome studies have been conducted, the overall weight of evidence supports the benefits of the practice,

- Outcome measures are reliable and valid and are administered consistently and accurately across all those receiving the practice,

- Outcome measures must address one of four categories; mental health prevention and treatment programs or services, substance abuse prevention and treatment programs or services, in-home parent skill-based programs or services, and kinship navigator programs;

- There is no case data suggesting a risk of harm that was probably caused by the treatment and that was severe or frequent.

If the program meets these minimum standards, the program will be evaluated and rated as one of four ratings. The four ratings are hierarchical in terms of amount and significance of evidence. The ratings criteria are: Does not meet criteria, Promising, Supported, and Well supported (Wilson et al. 2019).

These standards now require states to be responsible for designing, conducting, and publishing rigorous randomized controlled trials or quasi-experimental designs for any program that they wish to pull Title IV-E funding. Additionally, federal funding will only reimburse states for $50 \%$ of the cost of the evaluation, requiring each state government to fund the remaining $50 \%$ from local state budgets (Social Security Act as amended 2018). This shift of federal financial support pushed child welfare agencies to assess their current programs and strategies away from out-of-home care programs to programs that safely keep children in their homes while claiming federal dollars for approved Title IV-E programs only. While the sentiment behind this shift in focus is one that 
embraces the mission of child welfare agencies across the country to keep families together, it required large internal changes to be made in order for agencies to meet the rigor required in utilizing approved Title IV-E programs within their prevention work. Thus, although FFPSA prioritizes research and evaluation within the state government, there is a need for ethical oversight of research and an IRB accessible to the department-all while maintaining fiscal responsibility.

The need to conduct rigorous evaluation extends beyond new programs that have yet to be rated by the Title IV-E Prevention Services Clearinghouse. The law further states when the state pulls federal Title IV-E funding for programs rated as supported or promising, the state must submit a rigorous evaluation design to continually monitor and ensure fidelity to the practice model and determine outcomes achieved (Social Security Act as amended 2018). This requires states to continually invest in meeting evaluation requirements even after the program has been federally reviewed and found to lead to better outcomes for children and families. This constant cycle of evaluation and re-evaluation of each promising and supported program is required until a program meets the well-supported rating. Thus, states must continually evaluate a program until the well supported ranking has been met, which includes two rigorous evaluations with non-overlapping populations with at least one study showing sustained positive impacts one year post treatment (Wilson et al. 2019).

iii. Practice vs research does this research fall under IRB Review?

Under CFR 45 Section 46.102, not all research meets the requirements for IRB review. Research that is not required to be reviewed by an IRB includes research that is done in a practice setting, does not include the collection of identifying information, data is publicly available, or research that is conducted for the sole purpose of internal improvement of the agency or department. (Common Rule of 2018). Review by an IRB is needed both for research that is conducted or supported by a federal department/agency and for research that is not conducted or supported by a federal department or agency but falls under the definition of research set by The Common Rule of 2018. Under FFPSA, these rigorous evaluations must be "carried out in a practice setting" (FFPSA 2018) which implies the research may not automatically fall under IRB review. However, when we consider the populations that child welfare agencies work with - children, pregnant women, and potentially incarcerated individuals - these individuals fall under the category of a vulnerable population. Thus, state child welfare agencies are placed in the uncomfortable position of determining if IRB review must be sought for any program with the potential of Title IV-E funding. The Belmont Report argues "the general rule is that if there is any element of research in an activity, that activity should undergo review for the protection of human subjects" (National Commission for the Protection of Human Subjects of Biomedical and Behavioral Research 1979). This guideline argues that any state that may hope to use Title IV-E funding, must have access to an IRB to ensure the protection of vulnerable human subjects represented in child welfare.

As agencies must also publish their findings to meet FFPSA requirements, federal requirements are not the only governing body that child welfare agencies must navigate. Academic journal publishing guidelines also push the field towards needing IRB approval. Children and Youth Services Review, a popular journal in child welfare, states "All manuscripts that deal with human subjects must be accompanied by an Institutional Review Board (IRB) or Ethical Committee Approval, or national or regional equivalent in your geographic area" (Guide for Authors 2021). A review of journals in clinical psychology found that at least $40 \%$ of the journals sampled are likely to reject any human subjects research that has not been reviewed by an IRB (Osbourne and Luoma 2018). Due to the regulations dictated by federal research standards, and academic policies, IRB access for state researchers will be needed to meet the requirements of FFPSA.

\section{iv. Current Alternatives to Internal State IRBs}

While IRB review is needed in child welfare, internal state IRBs are not the only way in which state researchers can access IRBs. Currently, there are two main structures that provide IRB access to state 
agencies without internal IRBs: university partnerships and private IRBs. While each of these structures offer a stop gap measure, they are unsustainable and fiscally untenable under the new evidence-based driven environment needed in child welfare. When accessing a university IRB, many state programs may use employees that have adjunct faculty appointments with local universities or collaborate with a university researcher to gain access to an IRB. However, many universities may not allow adjunct faculty to access IRBs, and university collaborations only succeed when the interests of the state researchers align with the research interests of the university's Principal Investigator (PI) (Osbourne and Luoma 2018).

While private IRBs allow state researchers to avoid the need to obtain adjunct faculty appointments and like-minded research groups, they can be exceedingly costly. Osbourne and Luoma found that initial reviews provided by private IRBs could cost thousands of dollars, and this cost was noted as a barrier to practice-based research (2018). Additionally, FFPSA federal funding will only cover $50 \%$ of the administrative costs of the evaluation, (FFPSA 2018) requiring state agencies to fund the rest of this cost. Considering the amount of research that will need to be produced by state agencies under FFPSA, this highly expensive solution is unsustainable.

\section{v. Purpose of the Study and Research Questions}

As state child welfare agencies work to build the knowledge base of child welfare and meet the demands of FFPSA Title IV-E funding, state child welfare agencies will need access to a consistent and cost-effective IRB to adequately protect the vulnerable populations that come into child welfare. The following analysis seeks to understand how many state agencies have an internal, federally registered IRB and also ask the question: Of the state agencies that have an internal IRB, how many of these IRBs are accessible to the child welfare agency in the state? We explore how IRBs that are available to child welfare agencies are set up and function in the context of state government. Finally, we offer suggestions on how state agencies can implement internal IRBs to support state researchers within all departments with a specific focus on child and family serving agencies.

\section{Methodology}

If an IRB is going to sanction research on human subjects or their identifiable information, or receives funding from the United States Department of Health \& Human Services (USDHHS) or the United States Food and Drug Administration (FDA), and will be published, the IRB must be registered with the United States Department of Health \& Human Services Office for Human Research Protections (USDHHS/OHRP). Additionally, USDHHS/OHRP maintains a database for all registered IRBs, and Federal Wide Assurances (FWA), accurate up to the last sixty days. In this database, one can search for any federally registered IRB.

Information on state access to a federally registered IRB was done using the USDHHS/OHRP website, with both the basic and advanced search functions. For the first round, all fifty state names were put into the USDHHS/OHRP basic search bar under "IRB Name." For example, when looking for federally registered IRBs in Illinois, "Illinois" was put into the basic search bar labeled "IRB Name." Typically, state IRBs are named according to the state and department in which they reside. If this naming convention existed, the state would be marked as "1," which indicated the state had at least one federally registered IRB. To account for states that did not use this naming convention, each state was checked using the "advanced search" feature in which the name of the state was used in the "hosting" state search bar. This allowed the register to pull up all IRBs hosted within that state regardless of the naming convention.

To confirm the federal registry with acting state government practice, individual state's websites were searched for confirmation of the IRB and any documents explaining the IRB protocols and procedures. For states that had multiple IRBs within their state government, each individual state website pertaining to the IRB department was explored and confirmed.

While searching individual state websites, a few 
states claim to have IRBs that were not listed under the federal registry. More often than not, these IRBs are internal review committees that release data for use outside the state agency and cannot conduct evaluations or sanction Human Subjects Research. Considering these IRBs cannot be used to publish research or solely protect human subjects under a research framework, IRBs that are not federally registered were marked as 0 .

To determine if the child welfare agency within the states with IRBs were accessible to child welfare employees, the organizational chart, rules and procedures governing the IRB, and research scope of the IRB, were obtained for each state. If the child welfare department/office or agency fell under the IRB hosting department, the state was marked as having access to an IRB. If the child welfare department/office or agency did not fall under the hosting department, the state was marked as not having access. Individual state IRB coordinators were contacted when it was not clear if the IRB applied to both the hosting department and state child welfare agency. Additionally, a listserv that contains 67 child welfare data leaders was consulted for additional sources of IRB use within child welfare agencies, to ensure accuracy of state registries and alternative solutions. If an IRB could not be confirmed to be accessible to the child welfare agency, it was marked as unclear.

\section{Literature Review}

\section{i. Human Subjects and Ethical Underpinnings}

The following govern human subjects and how they should be handled in IRB proceedings: the Belmont Report (National Commission for the Protection of Human Subjects of Biomedical and Behavioral Research 1979) and HHS regulations under 45 CFR part 46 (The HHS Protection of Human Subjects in Research 2018). While this report and law are directed at the federal government, these laws are typically the base of state IRB policy in addition to any applicable state laws governing human subjects research.

The Belmont Report, authored in 1979, sets forth the ethical principles and guidelines which should be conducted to protect those human subjects of research. It emerged due to the enactment of the National Research Act, which was signed on July 12, 1974. That Act led to the development of the National Commission of the Protection of Human Subjects of Biomedical and Behavioral Research. The Commission's task was, in short, to ensure human subjects research considered the boundaries, appropriateness, participation, and informed consent as it relates to participants. The Belmont report sets forth the Commission's ethical principles and guidelines of these aforementioned topics and was made available on the Federal Register. The Report itself is immersed in policy and is not recommendation based.

An outgrowth of the Belmont Report is the HHS regulations under 45 CFR part 46. Subpart A of this regulation is known as the "Common Rule," which is "Basic HHS Policy for Protection of Human Research Subjects." The rest of the subparts are as follows:

- Subpart B: Additional Protections for Pregnant Women, Human Fetuses and Neonates Involved in Research

- Subpart C: Additional Protections Pertaining to Biomedical and Behavioral Research Involving Prisoners as Subjects

- Subpart D: Additional Protections for Children Involved as Subjects in Research

- Subpart E: Registration of Institutional Review Boards

The Common Rule was published in 1991 and has been updated and amended as of 2018. The Rule outlines how federal agencies must handle IRB research. The federal agency conducting the research is governed by their agency's regulations.

\section{ii. Federal Requirements of IRB}

The Common Under 45 CFR 46.107(a)-(f), a minimum of five individuals are required to serve on an IRB. In addition to the minimum requirement, the five individuals must meet diverse criteria. The following requirements are dictated by CFR A 10-1-16, 46.107 section IRB membership.

- No IRB can consist entirely of one gender, nor a single profession.

- An IRB must contain at least one individual who has a scientific background, and at least 
one individual who does not have a scientific background.

- The IRB must have at least one representative that is not affiliated with the hosting department, nor a family member of an individual on the committee from the hosting department.

- If research involves a vulnerable category of subjects, which includes children, pregnant persons, prisoners, handicapped or mentally disabled persons, the IRB must include an individual knowledgeable in these areas (CFR A 10-1-16).

- Research specifically involving prisoners as subjects must include a board member who is a prisoner or prisoner representative to review all research proposals on individuals in this population (CFR A46.305).

While the board must consist of a minimum of five individuals that span the aforementioned categories, IRBs must also designate special positions within their membership to coordinate the activities of the IRB. At least one member of the board must be labeled as the IRB Chairperson, and one individual must be labeled as the IRB Administrator. Depending on the institution's policies governing the IRB, one individual can occupy both roles. However, each role requires specific responsibilities, and the IRB Chairperson must be registered with USDHHS/OHRP.

The IRB Administrator is responsible for updating and maintaining federal registration of the IRB with USDHHS/OHRP, scheduling meetings, keeping appropriate documentation and minutes of convened meetings, communicating with researchers on IRB decisions, and ensuring department heads approve of any research submitted to the IRB. This position can be a voting or non-voting member when separate from the IRB Chairperson/s.

The IRB Chairperson/s is a position mandated by the Common Rule. The Chairperson/s is responsible for reviewing and assigning reviewers for expedited research, leading the meetings of the IRB and serving as the senior leading member of the IRB. In addition, the IRB can appoint alternates when full time members cannot attend, or when specific vulnerable populations are used in the research proposal.

\section{iii. Federal Procedure for Registering an IRB}

The majority of work to set up and register an IRB is done by the hosting agency. There is no cost to federally register an IRB and submission is done online. The "cost" of registering would be the time and effort needed to compile the information needed for the registration. The information required to register is as follows and comes from USDHHS/OHRP "IRB Registration Process FAQs" (n.d.). One must designate the hosting institution and provide all necessary contact information for the hosting institution. One must then designate the individual who will run the IRB and be responsible for maintaining the federal registration, typically your IRB Chairperson and/or Administrator. One must designate how many full-time employees are dedicated to the IRB. For state IRBs there are few full-time positions devoted to the IRB, with many employees splitting their IRB responsibilities with other responsibilities. However, states that hire and support a standalone IRB Administrator would record this individual as a full-time employee. The host must provide an estimate of the number of active protocols reviewed by the IRB and the number of active protocols conducted or supported by USDHHS. The host will need to provide a member list that includes the IRB Chairperson/s and additional members voting status, name, sex, highest earned degree, scientist vs. non-scientist, specialty, vulnerable population specialty, if applicable, and institutional affiliations. If the hosting institution dictates alternative members for the primary members, these individuals must also be reported to USDHHS/OHRP. Thus, for states that elect to add IRB responsibilities to current employee positions, there is no additional hiring cost for forming an IRB.

Once the policy and procedures are developed for the IRB, the hosting agency must also have a Federal Wide Assurance (FWA). A FWA is needed for any "institution engaged in human subjects research that is not exempt from the regulations and conducted or supported by any USDHHS agency must be covered by a OHRP FWA" ("Assurance Process Frequently Asked Questions (FAQs)", n.d.). An FWA indicates 
that an "institution commits to USDHHS that it will comply with the requirements in the USDHHS Protection of Human Subjects regulations at 45 CFR part 46" (Assurance Process Frequently Asked Questions (FAQs) n.d.). FWA registry is done online and must be updated every five years or if the IRB membership roster changes with no cost to the hosting agency. To register for an FWA, the hosting agency will need to submit the membership roster of the IRB, the policies and procedures governing the IRB including ethical principles, designate a Human Protections Administrator (IRB Administrator or Chair), the signature of the hosting department director, departments covered under the FWA, scope of the research covered under the IRB, and assurance of compliance with the terms of the FWA (Assurance Process Frequently Asked Questions (FAQs) n.d.).

\section{iv. General Structure of State Government Agencies}

Generally, IRBs are under the executive branch of state government in order to oversee the various departments. State agencies vary in terms of the size and position of the cabinet, departments, divisions, and/or agencies. Typically, a department is the highest agency within the executive branch. Divisions, agencies, and offices are nested within the various departments. Heads of the department are traditionally members of the cabinet. The most common departments across state governments are department of public health, department of agriculture, department of child services, and department of interior or environment. No two state governments are the same. It is also possible that these common departments can be divisions under a unifying department in some states. Each department is governed independently by its own internal policies and procedures. Thus, understanding the individual state government structure is pivotal to creating functional IRBs within the state.

For the purposes of understanding where child welfare agencies fall within state government structure, there are a few variations among states. A few states consider the child welfare agency a division under the Department of Health, or Department of Health and Human Services like the structure found in Michigan, Kentucky, and Georgia
("Michigan Department of Health and Human Services" 2021; "Cabinet for Health and Family Services" 2017; "Georgia Department of Public Health" n.d.). However, most states are organized with the child welfare departments as independent departments as seen in Indiana, Colorado, and Louisiana (Indiana Department of Child Services 2021; Child Welfare 2021; Department of Children \& Family Services n.d.). How a state develops the scope, policies and procedures governing the IRB is pivotal to the ability of the IRB to oversee multiple departments. Departments that are housed within the department of health or human services, must write their policies to cover all divisions under the department, and all researchers. Single child welfare departments only need to worry about writing policy that covers their individual department and employees. Departments that are made of multiple divisions require leadership buy-in from each executive of the division and increase coordination between divisions.

\section{Results}

\section{i. General State Access to IRB}

Using the federally registered database, we found that thirty-four States host at least one federally registered IRB and 16 States do not host any federally registered IRBs (Fig. 1). Twenty-two out of the forty federally registered state IRBs fall under a state's health department (Table 1) and only cover research conducted by the department of health, or employees of the department of health. However, for child welfare divisions that do not fall under the department of health's jurisdiction, very few states have IRBs that are accessible to the child welfare departments. Of the thirty-four states that do host at least one IRB, only eleven have IRBs that are accessible to the child welfare agency (Figure 2), due to the separation of departments. State IRBs policies and procedures are written to only cover the hosting department employees and research, thus, if a division/department is outside of the hosting division/department, the researchers of that agency will not have access to an IRB.

\section{ii. IRB Models Accessible to Child Welfare}

Of the eleven states in which child welfare agencies have access to an internal state IRB (Figure 2), three 
distinct models emerge: single department/agency IRB, inter-agency sharing agreement IRB, and a holistic multi-department IRB (Table 2). Single department/agency IRBs are internal IRBs hosted solely within a specific state department and only review research that includes that agency's employees, or internal data records. States with an accessible IRB to the child welfare department that host this type of IRB are Michigan, Minnesota,
Oklahoma, Utah, and Virginia (Table 2). Typically, these state agencies have more than one IRB within state government, and each IRB operates independently within the hosting department.

Table 1: State Government Departments with IRB Access within the United States

\begin{tabular}{|c|c|c|c|}
\hline State Government & $\begin{array}{l}\text { Federally } \\
\text { Registered } \\
\text { IRBs (\#) } \\
\end{array}$ & Hosting Department/s & $\begin{array}{l}\text { Accessible to State } \\
\text { Child } \\
\text { Department? }\end{array}$ \\
\hline Alabama & 1 & Public Health & Unclear* \\
\hline Alaska & 1 & Federal HHS Indian Affairs & No \\
\hline Arizona & 1 & Health Services & No \\
\hline Arkansas & 0 & NA & No \\
\hline California & 1 & Health and Human Services & Yes \\
\hline Colorado & 1 & Health and Environment & No \\
\hline Connecticut & 2 & Public Health, Office of Early Childhood & No \\
\hline Delaware & 0 & $\mathrm{NA}$ & No \\
\hline Florida & 2 & Health & No \\
\hline Georgia & 1 & Public Health & Yes \\
\hline Hawaii & 1 & Health & No \\
\hline Idaho & 1 & Health and Welfare & Unclear* \\
\hline Illinois & 1 & Public Health & No \\
\hline Indiana & 0 & NA & No \\
\hline Iowa & 0 & $\mathrm{NA}$ & No \\
\hline Kansas & 1 & Health and Environment & No \\
\hline Kentucky & 1 & Cabinet for Health and Family Services & Yes \\
\hline Louisiana & 1 & Health & No \\
\hline Maine & 0 & $\mathrm{NA}$ & No \\
\hline Maryland & 1 & $\begin{array}{l}\text { Department of Health and Mental } \\
\text { Hygiene }\end{array}$ & No \\
\hline Massachusetts & 2 & $\begin{array}{l}\text { Mental Health, Public Health and } \\
\text { Human Research Review Committee }\end{array}$ & No \\
\hline Michigan & 2 & $\begin{array}{l}\text { Public Health, Health and Human } \\
\text { Services }\end{array}$ & Yes \\
\hline Minnesota & 2 & Health, Human Services & Yes \\
\hline Mississippi & 1 & Health & No \\
\hline Missouri & 1 & Health and Senior Services & No \\
\hline Montana & 0 & NA & No \\
\hline Nebraska & 0 & $\mathrm{NA}$ & No \\
\hline Nevada & 0 & NA & No \\
\hline New Hampshire & 0 & $\mathrm{NA}$ & No \\
\hline New Jersey & 0 & $\mathrm{NA}$ & No \\
\hline
\end{tabular}




\begin{tabular}{|l|l|l|l|}
\hline New Mexico & 0 & NA & No \\
\hline New York & 2 & Health & No \\
\hline North Carolina & 2 & $\begin{array}{l}\text { Correction, Health and Human Services } \\
\text { Division of Public Health }\end{array}$ & Unclear* \\
\hline North Dakota & 1 & Health & Yes \\
\hline Ohio & 1 & Health & No \\
\hline Oklahoma & 3 & $\begin{array}{l}\text { Health, Human Services, Mental Health } \\
\text { Substance Abuse Services }\end{array}$ & Yes \\
\hline Oregon & 0 & NA & No \\
\hline Pennsylvania & 2 & Health, Education & No \\
\hline Rhode Island & 1 & Health & No \\
\hline South Carolina & 3 & $\begin{array}{l}\text { Public Safety, Mental Health, Health and } \\
\text { the Environment }\end{array}$ & No \\
\hline South Dakota & 0 & NA & No \\
\hline Tennessee & 0 & NA & No \\
\hline Texas & 2 & Health and Human Services & No \\
\hline Utah & 3 & Health, Human Services, Education & Yes \\
\hline Vermont & 1 & Agency of Human Services & Yes \\
\hline Virginia & 2 & Health, Social Services & Yes \\
\hline Washington & 1 & Health and Human Services & Yes \\
\hline West Virginia & 1 & Education & No \\
\hline Wisconsin & 0 & NA & No \\
\hline Wyoming & 0 & NA & No \\
\hline
\end{tabular}

*search of state website was unable to confirm federal USDHHS/OHRP registry. NA is not available or no IRB within the state.

Table 2: Type of IRB Model Accessible to Child Welfare

\begin{tabular}{|l|l|}
\hline State Governments & Type of IRB Accessible to Child Welfare \\
\hline California & Holistic Multi-Department \\
\hline Georgia & Inter-agency Sharing Agreement \\
\hline Kentucky & Holistic Multi-Department \\
\hline Michigan & Single Department/Agency \\
\hline Minnesota & Single Department/Agency \\
\hline North Dakota & Inter-agency Sharing Agreement \\
\hline Oklahoma & Single Department/Agency \\
\hline Utah & Single Department/Agency \\
\hline Vermont & Holistic Multi-Department \\
\hline Virginia & Single Department/Agency \\
\hline Washington & Holistic Multi-Department \\
\hline
\end{tabular}

An inter-agency sharing agreement IRB is an IRB in which the hosting department sets up sharing agreements across other state departments. These states typically hold one IRB within the state and have agreements with the other internal departments to access the hosting department's IRB. These IRBs can charge outside agency departments a fee for their review. States with this set up include Georgia and North Dakota (Table 2).

The third IRB model available to child welfare agencies, is a holistic multi-department IRB. Holistic multi-department IRBs are internal state IRBs typically hosted within a cabinet office that review 
research from all departments or agencies that fall under the cabinet. The states that operate a holistic multi-department IRB are California, Kentucky, Vermont, and Washington (Table 2). In order to understand the specific, make up of each IRB model a representative state was chosen based on accessibility to the IRBs policies and procedures within the state representing each IRB model.

Single Department/Agency IRB Oklahoma: Oklahoma operates its IRBs under the singular department/agency model. Oklahoma operates three federally registered IRBs hosted by its Department of Health, Department of Human Services, and Department of Mental Health and Substance Abuse Services. Child welfare services is a division under the Department of Human Services and through the Department of Human Services IRB, the child welfare agency is able to conduct and submit research. Each of these individual IRBs maintain independent membership, independent federal wide assurance, and independent policies and procedures. Each IRB supports an independent membership roster. The Department of Health IRB (OSDH IRB) hosts a nine-voting member IRB (Oklahoma State Health Department (OSDH) Institutional Review Board Members (as of $11 / 17 / 2020$ ) 2021), while the Department of Human Services (DHSIRB) hosts a seven-voting member IRB (340:2-39-8 Membership), and the Oklahoma Department of Mental Health and Substance Abuse Services (ODMHSAS IRB) hosts a minimum of five voting members (Title 450 Chapter 1 Administration 450:1-11-8). Each of the three Oklahoma IRBs also host individual chair and IRB administrator positions. Finally, each policy governing the three IRBs states that the hosting IRB will only cover employees and data under the hosting department IRB (Scope 310:10-1-2, Institutional Review Board n.d., 450:1-11-16), which dictates each IRB operates independently of other agencies and does not cover research or data outside of these department jurisdictions.

Inter-agency Sharing Agreement IRB, Georgia: The State of Georgia hosts a singular IRB in the Department of Public Health (Institutional Review Board 2018). The IRB consists of eight members with four alternates (IRB Board Members 2019).
Through an inter-agency agreement, Georgia's Department of Human Services, which houses the Division of Family \& Children Services, partners with the Georgia Department of Health IRB. Currently, one member of the board represents the Georgia Department of Family \& Children Services as a scientific member (IRB Board Members 2019). Through this agreement, both the Department of Public Health and the Department of Human Services can utilize the singular IRB without fees to either department unless the research is funded outside of a state agency (Institutional Review Board 2018).

Holistic Multi-Department IRB, Kentucky: The most widely used model of State IRBs accessible to child welfare agencies is a holistic, multi-department IRB (Table 2). Kentucky State Government is an example of how this model of IRB functions across multiple departments. The IRB is hosted within the Cabinet for Health and Family Services (CHFS IRB) (IRB Guidelines 2008). The CHFS IRB hosts a non-voting IRB Administrator who acts as a liaison between the cabinet and USDHHS/OHRP (IRB Guidelines 2008) and ensures all research projects reviewed by the IRB have been approved by the individual department heads. In addition to providing additional protections for CHFS clients and employees involved as subjects in research, the IRB also provides protections for subjects of research conducted, supported, endorsed, approved or sponsored by the Cabinet. This includes research conducted by individuals, students, employees, professors, universities, profit institutions, non-profit institutions, government agencies, or any other entity (IRB Guidelines 2008). There are six departments served within this cabinet and covered under the CHFS IRB, including the Department for Community Based Services which houses the child welfare division (Cabinet for Health \& Family Services Organizational Chart n.d.). All six departments are represented on the IRB membership roster and represent the majority of agencies that need IRB review within the state. 


\section{Discussion}

\section{i. Single Department/Agency IRB Model}

The single agency/department IRB model is beneficial for state governments that are not centralized under a cabinet, or overall department. States in which the departments of health, child welfare, correction and/or education are all separate entities can benefit from the single agency/department model. However, this model primarily benefits departments with a robust research team and staff. Smaller departments that only need a few research proposals reviewed per year or have a smaller research team may find that a single department/agency IRB is not sustainable due to the federal membership requirements, or time commitment of maintaining a full time IRB for few studies. The single department/agency model also requires the state to have significant access to both scientific and non-scientific individuals to serve across the multiple IRBs. Oklahoma's IRBs at a minimum are run by twenty-two individuals across the three, single department/agency IRBs. This model is the second most popular set up for State IRBs that are accessible to child welfare agencies (Table 2). However, this model allows agencies to specialize their IRB and only review proposals that relate to the specific department. This model promotes agency expertise and maximum knowledge on the research topic at hand.

\section{ii. Inter-agency Sharing Agreement Model}

The inter-agency sharing agreement model of Georgia allows state agencies to manage one federally registered IRB, across multiple departments. This model can be especially helpful if various departments only need a few proposals reviewed per year, while other agencies need more frequent access to IRBs. Additionally, this model offers the opportunity for state hosting agencies to receive funding from partnering agencies if needed by the hosting department of off-set IRB costs. This model can also assist state governments in which the departments are not under a single overarching agency or cabinet but have multiple departments that could use IRB access. This model can also be beneficial for departments with smaller research staff. However, this model of IRB, while using less state staff, does expand the type of research and expertise needed on the IRB member roster. It also requires the Administrator or Chair to coordinate across multiple departments.

\section{iii. Holistic Multi-Department Model}

The holistic multi-department IRB model works well in state agencies that have multiple departments under a singular cabinet. In addition, this model allows state agencies to host a singular IRB for multiple departments that all conduct research. These IRBs allow a single administrator who oversees the research across multiple departments to coordinate data and research requests. In this model, there is no singular hosting department, and no charges to the various departments within the cabinet for submissions. This model also allows the utmost transparency and singular guidelines for individuals accessing state data. With a singular IRB reviewing data requests and research requests, this model cuts down on potential variation between departments and procedures that could arise under the singular agency/department model or inter-agency sharing agreement model. The holistic model also allows fewer state employees to volunteer time while still covering multiple departments for IRB review.

\section{iv. IRB Benefit Research in Child Welfare}

With most states having access to at least one federally registered IRB (Figure 1), the process for obtaining an internal state IRB is attainable. However, this analysis found that sixteen states do not have access to an IRB suggesting significant opportunity to expand research capabilities within those states. The majority of state agencies host IRBs

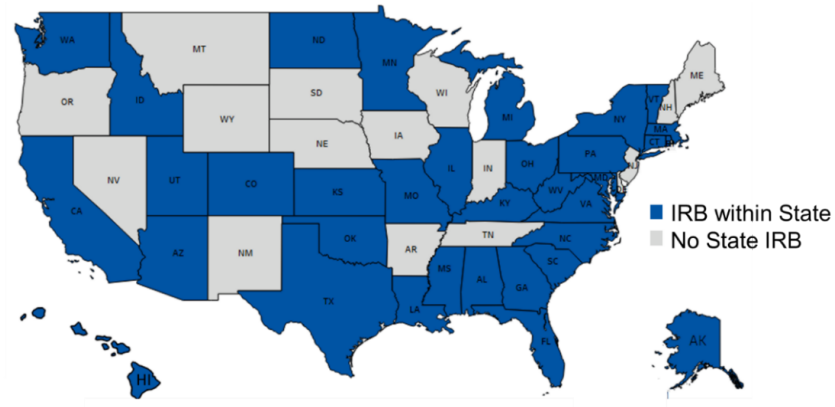

Figure 1: States with an internal Institutional Review Board.

within their department of health (Table 1), and while this indicates access to IRBs for public health 
employees, this leaves multiple departments and state researchers without access to IRB review. While child welfare faces the most immediate need for IRB access due to FFPSA, several state departments lack access to IRB. Only three states have IRB access within the Department of Education, and only one state operates an IRB accessible to the Department of Correction (Table 1), both fields in which Human Subjects Research is pivotal to the department and operation. Other state departments that could benefit from IRB oversight are the department of adult and aging services, department of Medicaid and any other human services-based department. With only eleven of thirty-four states hosting IRBs accessible to child welfare (Figure 2) and thirty-four states hosting any IRB (Figure 1), there is capacity for IRB access across departments and state governments.

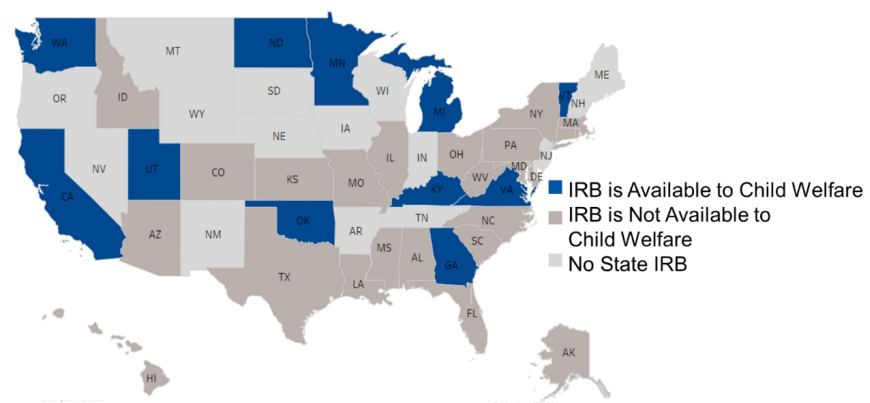

Figure 2: States in which the child welfare agency has access to an Institutional Review Board

\section{v. Protection of Human Subjects and their Personal Information}

IRBs are tasked with protecting human subjects involved in research. State governments house massive amounts of information that could be used to study, evaluate, and research policies and programs to better the lives of the constituents they serve, but this information should not be accessed lightly. The amount of information collected in these systems is collected for services, or the betterment of policy and practice, and not research. Thus, it is imperative that researchers within these agencies have access to an IRB to give protections to the human subjects' information, even when not immediately required. Osborne and Luoma argue that there are multiple benefits to having practice-based research reviewed by an IRB, even if not federally required including, ensuring the rights of human subjects are protected, ensuring research methodologies are ethical, alerting researchers to specific state and local laws, managing potential legal liability to protect both researchers and research subjects from misconduct, and allowing for dissemination of findings in academic journals (Osborne and Luoma 2018).

The Belmont report explicitly expresses the need to protect human research subjects based on respect for persons, beneficence, and justice (National Commission for the Protection of Human Subjects of Biomedical and Behavioral Research 1979). These recommendations have been approved by the Common Rule further articulating the need to protect human subjects, and their personal information. It is critical to think about the populations that state agencies serve. Child welfare agencies interact with all three vulnerable populations defined by the Common Rule: children, pregnant women, and incarcerated persons. Access to an IRB to evaluate state child welfare research further protects human subjects, and their personal information.

\section{vi. Expanding Research Capacity Outside of Academia} Not only will access to an IRB within government agencies help government researchers, but they expand the ability to support researchers publishing outside of academia. . By expanding the ability for government scientists to disseminate findings and share results, this further strengthens the field of evidence for any discipline and meets the rigorous requirements of FFPSA for child welfare. In 2003, the Op-Ed of the Journal of Epidemiology and Community Health discussed the need to allow state researchers to distribute their research widely, opining that "Government agencies should encourage and facilitate government scientists to publish their findings in peer reviewed journals." (Choi et al. 2003). The need to publish evidence-based evaluations within state agencies is needed in the field of child welfare, and the greater child welfare discipline can benefit from added researchers evaluating and publishing their work. 


\section{Recommendation for State to Build Internal IRBs}

This analysis revealed states fall into two categories to provide IRB accessibility to child welfare: states without any IRBs and states with IRBs where policies do not support inter-department collaboration. Considering only eleven states have accessible IRBs for child welfare agencies, this analysis reveals the majority of states can implement changes to expand IRB access to allow state child welfare researchers to meet the rigorous demand of FFPSA. Through successfully engaging stakeholders and using other states' published resources, states can implement IRBs without large increases in funding. Federally registering an IRB does not cost the hosting agency additional funds, and many states can use existing employee expertise to oversee the IRB. Due to statutes and federal law, federally registered IRBs must post their policies and procedures as well as contact information governing the IRB. Almost all of the states' IRB policies and procedures were available online and can be used as blueprints for other states making modifications to an existing IRB or creating an IRB.

The key to successful implementation regardless of current IRB capacity is bringing the correct stakeholders and decision makers to the table. An implementation champion of the IRB will be needed who is either familiar or ready to learn the federal regulations governing the IRB and prepared to champion building the policy or procedures. Ideally, this is a scientist/researcher within the state with previous experience submitting IRB procedures. Next the implementation champion must engage the executive leaders of the department, and their head of research/chief scientists to learn about the research needs of the agency and obtain cabinet approval. Once cabinet approval is obtained, the cabinet can take the request to the governor's office for full state approval. Failure to accurately engage these decision makers can cause the implementation to fail. Below we suggest the additional following recommendations depending on the specific category each state falls into:

- For the sixteen states that do not currently have any federally registered IRBs, state administrators should start by assessing the number of departments that conduct research and identifying an implementation champion. Once these departments and individuals have been identified, administrators must evaluate the state department organization chart to identify if the departments fall under a singular cabinet or operate independently. The set-up will determine which model of IRB would be appropriate for the state.

- States in which the departments are separated from each other may wish to explore singular department/agency IRBs or inter-agency sharing agreements depending on the number of researchers within each department and the relationships between the departments.

- For states that have departments under a single cabinet, a holistic multi-department IRB can be created to oversee multiple departments within the state.

After deciding the most functional model for the state, administrators should identify if an IRB administrator position is needed separate from the chair, which would be most likely under a holistic multi-department IRB, or inter-agency sharing agreement IRB. States must consider the availability of the individual already within the state or create a position. Once these major structural decisions are evaluated and considered, state administrators can model their IRB policies and procedures based on existing state IRBs.

Without careful planning and full understanding the organizational structure and research capacity of each agency can cause an IRB to not be built, or non-functional. Without carefully building an IRB that operates in the context of each state, research capacity will not be built, and state researchers will fail to conduct ethical evaluations. The consequences for child welfare are even more dire. Without access to an IRB, state child welfare agencies will be unable to pull federal funding for their prevention programs.

The thirty-four states with at least one IRB are best positioned to evaluate the structure of the IRB and use existing resources to expand capacity to other state departments. Depending on the number of 
reviews needed by additional agencies, the existing IRB can enter an inter-agency sharing agreement and appoint additional members to the current committee. While the states will need to update both their federal IRB registry and FWA, both of these processes are free and would restart the clock on federal registration.

\section{Conclusion}

The majority of states (68\%) use internal IRBs to support state research and researchers. However, this analysis found a significant gap in the accessibility of these IRBs to support state child welfare agencies. Only eleven states have an internal IRB that is accessible to the child welfare department. For states to meet the demands of

\section{References}

Office for Human Research Protections. United States Department of Health and Human Services. n.d. "Assurance Process Frequently Asked Questions (FAQs)". Accessed March 29, 2021.

https://www.hhs.gov/ohrp/register-irbs-and-obt ain-fwas/fwas/assurance-process-faq/index.html

Cabinet for Health and Family Services. n.d. Organizational Chart. Accessed March 29, 2021. https://personnel.ky.gov/DHRAOrgCharts/OC-53 .pdf

Colorado Department of Human Services. Our Services. Child and Family Services. 2021. "Child Welfare." Accessed March 29, 2021.

https://cdhs.colorado.gov/our-services/child-an d-family-services/child-welfare

Choi, Bernard C. K., David V. McQueen, and Irving Rootman I. 2003. "Bridging the gap between scientists and decision makers." Speaker's Corner. Journal of Epidemiology and Community Health. 57: 918 http://dx.doi.org/10.1136/iech.57.12.918

Department of Children and Family Services. n.d. "About Us." Accessed March 29, 2021. http://www.dss.state.la.us/page/7

Families First Prevention Services Act, 42 U.S.C. Sections 621 et seq. 2018.

Georgia Department of Public Health. n.d. "About DPH." Accessed March 29, 2021. https://dph.georgia.gov/about-dph

Children and Youth Services Review. 2021. "Guide for Authors."

https://www.elsevier.com/iournals/children-and -youth-services-review/0190-7409/guide-for-aut hors
FFPSA, each state must build access to an internal state IRB. The twenty-three states that already have an internal state IRB, which is not accessible to the child welfare agency, can expand their existing IRB to include the child welfare agency. For the sixteen states that do not have any IRBs, they can build an IRB specific to their state by analyzing the organization chart of departments, evaluating agency needs and number of state researchers within each department, and using the vast, free, resources of policy and practice documents located on state websites. Creating and maintaining a state IRB will increase the research capacity of child welfare agencies to meet the demands of FFPSA and contribute to greater capacity of researchers outside academic institutions.

Human Subjects Protection. 310 Ok. Chap. 10. (Adopted March 14, 2002).

Indiana Department of Child Services. 2021. "About DCS." Accessed March 29, 2021. https://www.in.gov/dcs/2370.htm

Georgia Department of Public Health. 2018 "Institutional Review Board." Accessed March 29, 2021 https://dph.georgia.gov/institutional-review-boa $\underline{\mathrm{rd}}$

Institutional Review Board, Oklahoma Human Services. n.d. "About DHSIRB." Accessed March 29, 2021 http://www.okdhs.org/IRB/Pages/default.aspx

IRB Board Members 2019: Georgia Department of Public Health. "About DPH." Accessed March 29, 2021. https://dph.georgia.gov/irb-board-members

Cabinet for Health and Family Services (CHFS) Institutional Review Board for the Protection of Human Subjects. n.d. "IRB Guidelines." Accessed March 29, 2021. https://chfs.ky.gov/agencies/os/omb/Pages/irb. $\underline{\operatorname{aspx}}$

Office for Human Research Protections. United States Department of Health and Human Services. n.d. "IRB Registration Process FAQs." Accessed March 29, 2021. https://www.hhs.gov/ohrp/regulations-and-poli cy/guidance/faq/irb-registration-process/index. $\underline{\mathrm{html}}$

Michigan Department of Health \& Human Services. 2021. "Abuse and Neglect." Accessed March 29, 2021. https://www.michigan.gov/mdhhs/0,5885,7-339 $-739717119---00 . h t m l$

National Commission for the Protection of Human Subjects of Biomedical and Behavioral Research. 1979. The Belmont report: Ethical principles and 
guidelines for the protection of human subjects of research. Bethesda, Md.: The Commission.

Oklahoma State Department of Health (OSDH) Institutional Review Board Members as of 11/17/2020. Accessed March 29, 2021. https://oklahoma.gov/health/organization/instit utional-review-board/board-members.html

Osborne, Travis L. and Jason B. Luoma. 2018. Overcoming a Primary Barrier to Practice-Based Research: Access to an Institutional Review Board (IRB) for Independent Ethics Review. Psychotherapy. 55(3):255-262.

http://dx.doi.org/10.1037/pst0000166v

Protection of Human Subjects, 45 C.F.R. 46 (Common Rule of 2018 cites here:

https://www.hhs.gov/ohrp/regulations-and-poli cy/regulations/45-cfr-46/revised-common-ruleregulatory-text/index.html)

Social Security Act, Title IV-E, 42 U.S.C. 670 et seq. 2018.

Social Security Act, Title IV-E, 42 U.S.C. 670 et seq. 1995.
Oklahoma Department of Mental Health and Substance Abuse Services. n.d. "Title 450, Chapter 1 Administration." Accessed March 29, 2021 https://oklahoma.gov/content/dam/ok/en/odm hsas/documents/a0002/chapter-1-final-effective -9-5-18.pdf

Wilson, S.J., Cristofer S. Price, Suzanne E. U. Kerns, Samuel R Dastrup, and Scott R. Brown. 2019. "Title IV-E Prevention Services Clearinghouse Handbook of Standards and Procedures, Version 1.0." Office of Planning, Research, and Evaluation Administration for Children and Families, U.S. Department of Health and Human Services. https://www.acf.hhs.gov/sites/default/files/doc uments/opre/psc handbook v1 final $508 \mathrm{compl}$ iant.pdf

340:2-39-8 Membership Revised 9/15/2020. Accessed March 29, 2021. https://oklahoma.gov/okdhs/librarv/policy/curr ent/oac-340/chapter-2/subchapter-39/members hip.html

Elisabeth S. Wilson studied Biology and Sociology at DePauw University where she was introduced to interdisciplinary policy research through her Senior Thesis: Legislators as Peer Reviewers: How legislators influence scientific research produced by the United States Department of Agriculture (USDA). She pursued her MS degree from North Dakota State University studying how agricultural practices impact pollinator nesting behavior. Now, Elisabeth is the Senior Research Analyst for the Indiana Department of Child Services where she works to build research capacity within child welfare and state government. Elisabeth hopes to dedicate her career to expanding research access and informing decision makers on evidence-based decision making.

Heather Hendley graduated with a BA in Psychology and started her journey with the Department of Child Services as a family case manager in 2010. She has been instrumental in building and ultimately leading Indiana's statewide program for older youth, Collaborative Care. Presently, Heather is the Assistant Deputy Director of Strategic Solutions and Agency Transformation where she manages federal reporting, continuous quality improvement, quality service and assurance, and research and evaluation for the Department. Heather hopes to coordinate efforts across these disciplines to inform large scale changes within the Department to positively impact the lives of children and families.

Rachel D. Russell received degrees in Anthropology, English, and French from Purdue University. She obtained her juris doctor degree from Valparaiso University School of Law. She has served as a paralegal in public defense, clerked at the Lake County Public Defender's Office in Crown Point, Indiana where she assisted with death penalty cases, and externed for Margret G. Robb at the Indiana Court of Appeals. After law school, Rachel became a public health lawyer and deputy general counsel for several years at the Indiana Department of Health. She began her tenure at the Indiana Department of Child Services in 2017 as Deputy General Counsel and Ethics Officer.

Heather H. Kestian has been a licensed attorney in good standing with the Indiana Supreme Court since October 2008. She joined the Indiana Department of Child Services (DCS) in 2008 as a local office attorney where she represented the agency in Child in Need of Services (CHINS), Termination of Parental Rights (TPR) proceedings, and in appellate matters. She has served as an Administrative Law Judge for DCS, a Local Office Director for DCS, and the Collaborative Care Field Director. She currently serves as the Deputy Director for 
Strategic Solutions and Agency Transformation (SSAT). She graduated Cum Laude from the University of Toledo College of Law in May 2008.

Terry J. Stigdon MSN, RN, was appointed as director of the Indiana Department of Child Services in early 2018. Stigdon has implemented changes aimed at offering the best service to Hoosier children and families. As a result of her efforts the state has seen a decrease in children in residential treatment and foster care. Prior to her appointment, she spent nearly 20 years at Riley Hospital for Children. Her work took her to the pediatric intensive care unit as well as the emergency medicine and trauma center. Stigdon, a Chicago native, holds a bachelor's degree in nursing as well as a master's degree in nursing leadership and management.

\section{Acknowledgements}

Thank you to Noelle Russell for her thoughtful review of the manuscript. Thank you to all the IRB coordinators who communicated with us throughout this analysis. Thank you to Peter Serles and Nabanita Nawar for their thoughtful reviews of the manuscript.

\section{Disclaimer}

All authors work for the Indiana Department of Child Services; however, no individual's salary or compensation is dependent on the analysis or publication of the manuscript. 